\title{
BULK POLYMERIZATION OF CHOLESTERYL ACRYLATE
}

Lately there has been an increasing interest in the polymerization of mesomorphic monomers (1-4). Since esters of several steroids are known to exhibit liquid crystalline behavior and only a few polymers incorporating the cholesteryl moiety are known (5-6), we focused our attention on cholesteryl acrylate. A recent article on the same subject by Toth and Tobolsky (7) prompted us to report our results.

Cholesteryl acrylate was prepared in $70 \%$ yield by refluxing cholesterol and an excess amount of acryloyl chloride in benzene. The ester was isolated following the method of Front and Daubert (8). Repeated crystallization from ether/ethanol yielded a pure product, proved by elemental analysis.

Found:

Calculated for $\mathrm{C}_{30} \mathrm{H}_{48} \mathrm{O}_{2}(440.7)$ : C $81.8 ; \mathrm{H} 11.0 ; 07.3 \%$

IR and mass spectra were consistent with the expected structure.

A mesomorphic phase between $122 .{ }^{\circ} \mathrm{C}$ and $125^{\circ} \mathrm{C}$ was observed through a hot stage microscope with crossed nicols. The enantiotropic liquid crystalline phase appeared to have the cholesteric plane texture. Thermograms obtained with a Du Pont differential thermal analyzer were in agreement with the observed transition points. The thermal properties of the acrylate ester are given in Table I.

The small endotherm at $66^{\circ} \mathrm{C}$, which will be investigated further, was reproducible when the maximum temperature of the heating cycles did not surpass $75^{\circ} \mathrm{C}$. On heating the sample up to $150^{\circ} \mathrm{C}$ a broad exotherm, due to polymerization of the monomer, between $128^{\circ} \mathrm{C}$ and $150^{\circ} \mathrm{C}$ was observed. The positions and areas of the exotherms in the cooling curve were dependent on the rate and the temperature and time interval of the sample in its isotropic phase, in agreement with the statement of Toth and Tobolsky (7). However, we found both by DTA and microscopic measurements the temperature of the liquid-mesophase transition to be ca. $125^{\circ} \mathrm{C}$, contrary to the temperature of $90^{\circ} \mathrm{C}$ reported by those authors. Cooling at a rate of $5^{\circ} \mathrm{C} / \mathrm{min}$ immediately after the sample had reached $127^{\circ} \mathrm{C}$, resulted in the data given in Table I.

In order to investigate the effect of monomeric order in the mesophase on polymerization rate and product orientation, thermal polymerization in bulk was carried out during four hours in the solid state (at $120^{\circ} \mathrm{C}$ ), in the mesomorphic state (at $123^{\circ} \mathrm{C}$ ), and in the isotropic state (at $126^{\circ} \mathrm{C}$ ). Polymerization was performed in vacuo after repeated flushings with ultrapure nitrogen. When polymerization took place at $123^{\circ} \mathrm{C}$ during four hours 


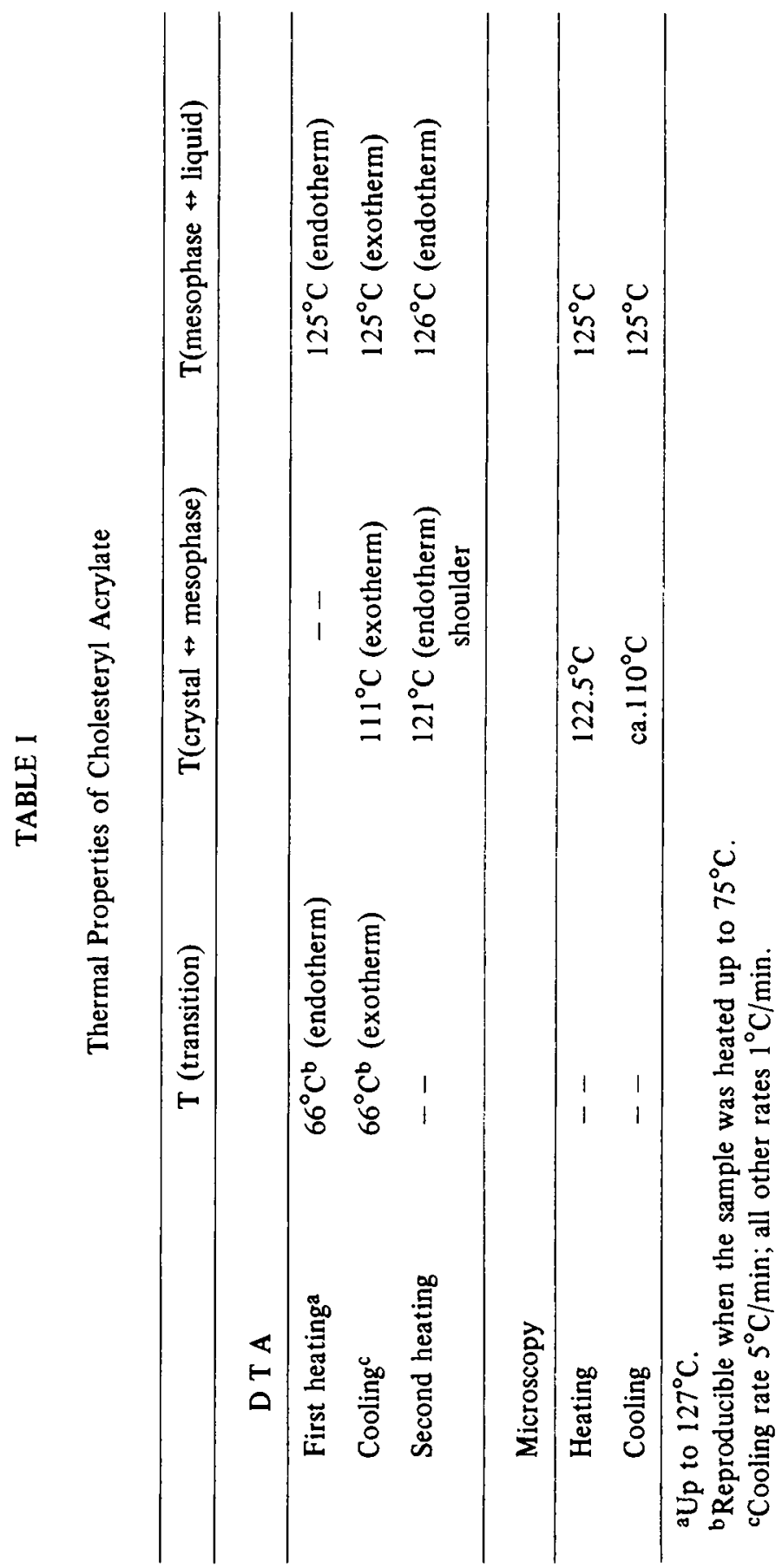




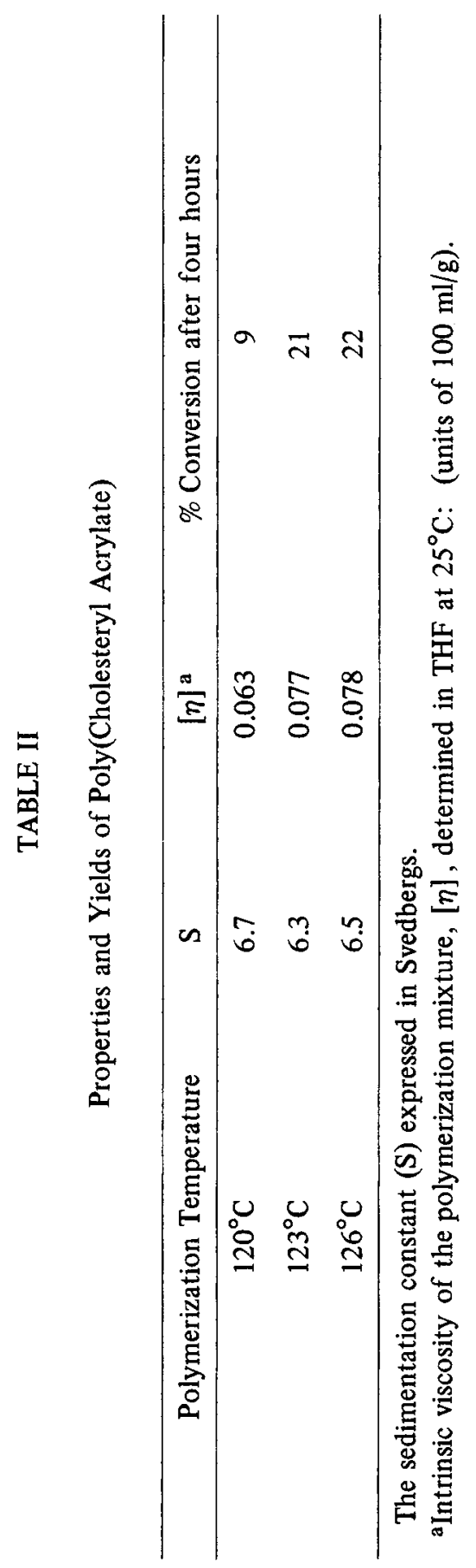


without the exclusion of air, only insoluble products were obtained.

Intrinsic viscosities of the reaction mixtures were measured in tetrahydrofuran using Ubbelohde capillary type viscometers. A reaction time exceeding four hours did not change the viscosities. The Beckman-Spinco Model $\mathrm{E}$ analytical ultracentrifuge, equipped with Schlieren optics, was utilized for determination of sedimentation constants. From the areas under the sedimentation peaks the fractions converted monomer were calculated. The results are given in Table II. The sedimentation peaks showed a narrow molecular weight distribution.

In summary, in all three phases the polymer obtained possessed a sedimentation constant of about $6.5 \mathrm{~S}$, indicating average molecular weights in the order of $10^{5}$. Less monomer was converted in the solid phase than in the liquid crystalline and isotropic phases. A significant difference in conversion for the polymerization in the mesophase and the isotropic phase was not found. A similar result has been reported by Paleos and Labes, who investigated the polymerization of $\mathrm{N}-(\mathrm{p}-$ methoxy-o-hydroxy-benzylidene)-p-amino styrene (9).

The results of further investigations on this subject will be given in a forthcoming paper.

\section{References}

(1) Y. B. Amerik and B. A. Krentsel, J. Polymer Sci., C,16, 13831392 (1967).

(2) Y. B. Amerik, L. I. Konstantinov, and B. A. Krentsel, J. Polymer Sci., C,23, 231-238 (1968).

(3) C. Sadron, Pure and Applied Chem., 4, 347 (1962).

(4) C. M. Paleos, T. M. Laronge, and M. M. Labes, Chem. Comm., 1115-1116 (1968).

(5) M. M. Dhar and K. L. Agarwal, Steroids, 3, 139 (1964).

(6) V. K. Naithani and M. M. Dhar, Biochem. Biophys. Res. Comm., 29, 368-372 (1967).

(7) W. J. Toth and A. V. Tobolsky, J. Polymer Sci., B,8, 289-291 (1970).

(8) J. S. Front and B. F. Daubert, J. Am. Chem. Soc., 67, 1509-1510 (1945).

(9) C. M. Paleos and M. M. Labes, "Polymerization of a nematic liquid crystal monomer," Third Inter. Liquid Crystal Conf., Berlin, W.-Germany, August 24-28, 1970.

Polymer Division

Dept. of Chemical Technology

Technical University of Twente

Enschede, The Netherlands
A. C. de Visser

J. Feyen

K. de Groot

A. Bantjes

Received September 16, 1970. 